\title{
Organizational Change and the Meaning of Time ${ }^{(1)}$
}

\author{
José Roberto Gomes da Silva* \\ E-mail address: jrgomes@iag.puc-rio.br \\ IAG - Pontifícia Universidade Católica do Rio de Janeiro \\ Rio de Janeiro, RJ, Brazil \\ Ursula Wetzel \\ E-mail address: ursula@coppead.ufrj.br \\ Instituto COPPEAD - Universidade Federal do Rio de Janeiro \\ Rio de Janeiro, RJ, Brazil
}

\begin{abstract}
This paper probes into the social process of sense making in changing organizations, trying to observe how participant individuals interpret contextual events and configure their notion of time. This notion of time then interacts with the dynamics of the lives of individuals and contributes to the adaptation to the new reality they are facing. The study was conducted in eight organizations and data were collected by means of 133 in-depth interviews with participants in the change processes. Results indicate that individuals establish a reference to central events in their attempt to make sense out of changes and in their effort to adapt to the new situation. In accordance with Lewis and Weigert (1981), the results also indicate the dominance of institutional time over interaction time as well as over self time. Finally, the results suggest that such configurations of time are influenced by official organizational rhetoric and by actions in change management.
\end{abstract}

Key words: time; organizational change; sense making; change management.

Received 1 December 2004; received in revised form 15 April 2005.

Copyright (C) 2007 Brazilian Administration Review. All rights reserved, including rights for translation. Parts of this work may be quoted without prior knowledge on the condition that the source is identified.

*Corresponding author: José Roberto Gomes da Silva

Rua Marquês de São Vicente, 225, Gávea, 22453-900, Rio de Janeiro, RJ, Brazil. 


\section{INTRODUCTION}

Organizational changes have been one of the most analyzed fields by management sciences in recent decades. In the attempt to help organizations better manage change processes, literature was developed concerning the proposition of models that seek to raise the effectiveness of actions, reduce supposed human resistance or even equate the different types of problems that keep organizations from attaining their goals (Allaire \& Firsirotu, 1989; Kotter, 1995).

This managerial outlook has been criticized by a number of authors as it does not provide better understanding of feelings (Ketz de Vries \& Balazs, 1999; Silva \& Vergara, 2003; Vince \& Broussine, 1996), the real difficulties (Armenakis \& Bedeian, 1999; Bareil \& Savoie, 1999), identity issues (Rouleau, 1999), construction of sense (Demers, 1993; Ford \& Ford, 1995; Weick, 1995; Weick \& Quinn, 1999) and interpretations (Isabella, 1990) of those who constitute the most important element in the dynamic of organizational changes: the people who participate in them.

Weick and Quinn (1999) also observe that the concept of organizational change has been characterized as a temporal phenomenon, or set of events whose result is described as the construction of a new concept from an existing concept. According to Giddens (1984), it is in a perspective of space and time that social structure is reproduced. In this sense, the understanding of the dynamic of society at its different levels of analysis is only possible through a space-time perspective:

I think it is a mistake to regard encounters in circumstances of co-presence as in some way the basis upon which larger, or 'macrostructural', social properties are built. (...) But neither, on the contrary, is interaction in situations of co-presence simply ephemeral, as contrasted to the solidity of largescale or long-established institutions. (...) The opposition between 'micro' and 'macro' is best reconceptualized as concerning how interaction in context of co-presence is structurally implicated in systems of broad time-space distanciation (Giddens, 1984, p.xxvi).

To Giddens (1984), the essence of reflexivity and conscience of the agent is in his capacity to position himself in space and time. The reflexivity of the agent concerns self awareness, the exercise of the capacity to position his action and, simultaneously, the capacity to watch, to control the ongoing flow of social life and contexts, positioning himself therein. And, concomitantly, it is the use of this reflexivity, in situations of interaction, that makes agents capable of producing and reproducing social systems (Giordano, 1998).

Thus, the aim of this study is to attempt to obtain better understanding of the development process of this reflexivity, the construction of a level of conscience that helps individuals to assume the condition of competent agents, reducing their difficulties and anguish.

Time is focused on as the main dimension of analysis, albeit recognizing, as observed by Lee and Liebenau (1999), that time and space are not two independent dimensions, which makes the characterizations of space enter all the main discussions.

Also according to Lee and Liebenau (1999), an important criterion for differentiation between organizational studies that deal with the temporal issue concerns how they classify the functional role of time. In some studies, time is dealt with as an independent variable and the focus is directed to the understanding of how several temporal factors interfere in the individual behaviors or groups or organizations. In other studies, time takes on the characteristics of a dependent variable and greater interest lies in the investigation of how the different individual, situational and environmental factors in organizations influence the way in which individuals conceive, experience and utilize time. Therefore, by focusing on the way in which individuals configure the notion of time in the light of organizational changes and how these configurations simultaneously influence the meaning that individuals attribute to the changes, this study assumes the notions of time and meaning of changes as social constructions that bear no relationship of unidirectional causality and which cannot, therefore, be treated as dependent or independent variables. 


\section{The Collective, Dynamic and Relative Notion of Social Time}

Lee and Liebenau (1999) state that it is impossible to carry out a sociological analysis of the time dimension based only on the metaphor of clock time. In the view of Sorokin and Merton (1937), the objective concept of astronomical time, 'calendar time', held by many as a universal reference, represents only one among many concepts of time. To these authors, the conception of time, seen as something uniform, infinitely dividable and continuous, offers few possibilities to contribute to a better understanding of social realities. Therefore, they defend the use of the concept of social time. Lewis and Weigert (1981) define social time as a 'form of human meaning constructed in the processes of interaction, limited by the physical realities of the organism and nature and structures in institutions and organizations of each society'(p. 450). Newton (2003) observes that the notions of natural time and social time cannot be seen as totally separate dimensions, although they need to be recognized as different.

Lewis and Weigert, like Sorokin and Merton (1937), consider, however, that the units of measurement of time are constructs that are set by the dynamic of collective life and that we tend to utilize the devices for counting physical time only to 'keep time'(Lewis \& Weigert, 1981, p. 433) between social events of our interest.

Sorokin and Merton (1937) also emphasize that social time differs with the common beliefs and habits of each group. Block, Buggies and Matsu (1996) observe, for instance, that, even considering the high degree of cultural homogenization found in world society nowadays, the notions of time vary from culture to culture in terms of perspective, orientation of values, flow of life, judgement of duration and meaning attributed to temporal terms and concepts.

To a number of authors (Blount \& Janick, 2001; Sorokin \& Merton, 1937) social time is a collective construction which, different from calendar time, cannot be understood as something continuous but rather as something interrupted or referenced by critical dates. The relativity of the notion of social time is thus expressed by Sorokin and Merton:

social time expresses the change or movement of the social phenomena in terms of other social phenomena taken as points of reference. In the course of our daily activities we often make use of these means of indicating points of time. "Shortly after the World War", "I'll meet you after the concert" (...) are all related to social, rather than astronomical frames of reference (Sorokin \& Merton, 1937, p.618).

The notion of social time utilized by these authors is, therefore, dynamic, discontinuous and relative, also reflecting collectively experimented changes, the significance of which is expressed through language that is also commonly constructed. To them, the reference of calendars only acquires meaning when expressed in terms of social time.

In epistemological terms, this need for the relativity of the notion of time to be recognized represents a challenge to many of the assumptions of society and modern science. Hassard (2001) states that, in the modern perspective and above all in the industrial age, the predominance of the notion of quantitatively measurable linear time has been predominantly assumed, according to which 'the past is not repeated, the present is transitory and the future is infinite and unexplorable'(Hassard, 2001, p. 133).

To Sorokin and Merton (1937), an exclusively quantitative measure of time does not cater for the qualities with which the various time units are engendered by the members of a group. This does not mean that social time has no quantitative aspects, but it does not appear reasonable that it should be seen simply as quantity, homogenous in its parts, always comparable to itself and exactly measurable. 
In the judgements of time, there are subjective considerations concerning opportunity, continuity, constancy and similarity, in addition to other values attributed to the different intervals of time that result in their not being seen equally in terms of duration. Glucksmann (1998), for instance, calls attention to the incommensurability of the use of time when the environment in which the subject is inserted - type of work, socioeconomic category, working relationships - is taken into consideration. Thus, social time needs to be seen as a qualitative model and not simply as a quantitative variable (Blount \& Janicik, 2001; Glucksman, 1998; Hassard, 2001; Sorokin \& Merton, 1937).

\section{The Structures And Meanings Of Social Time}

Lewis and Weigert (1981) introduced a proposal for the construction of the theory of social time, which they described as a 'paradigm for the sociology of time'. To these authors, social time is determined by the different levels of activity of life in society: the individual level, the group level and the cultural level. Each of these has its own forms of social time: at the individual level, 'self time'; at the group level, 'interaction time', which corresponds to informal interactions, and 'institutional time', which results from bureaucracy and other formal organizational mechanisms; at the broader sociocultural level, 'cyclic time' (days, months and seasons). The terms self time and interaction time, therefore, are at the micro level of social reality, while institutional time and cyclic time are representative of the macro level of this same reality.

Self time may be defined as the product of meaning attributed by the individual. Self time is not homogenous since distant events in the past can be represented in the conscience just as memories of what took place moments ago, and future events may be translated into immediate expectations. Likewise, it is not a necessarily sequential time, as it can bring an event from the past or the future to the present and make it into a different event. The mind, therefore, would be capable of manipulating the events in time 'as if they were ordinary material objects that can be moved around at will' (Lewis \& Weigert, 1981, p. 436).

Interaction time is the result of the meaning constructed through informal meetings between individuals and is imposed partially on the self time of each one concomitantly to the fact that, as an intersubjective reality, it is subject only partially to the experience and control of each individual. Social norms regulate their flow and characteristics of the social structure - such as the status of the interlocutor and the cultural values of a society - that are included in the interaction. In other words, each instance of interaction act is embedded in larger social acts. In this way, each participant in the interactions needs to be adjusted or synchronized, in temporal terms, according to these norms of the larger structure. This need to adjust or synchronize is, however, influenced by the positioning of each individual in the larger social structure and, therefore, varies according to characteristics such as social class or age group.

Self time and interaction time (micro level) are, however, embedded in the temporal orders of social institutions and culture (macro level). According to Lewis and Weigert, in industrial society, there are marked differences between the structures of institutional time and cultural time in terms of form and scope. In the institutional sphere, each organization constructs its own rules and ways of structuring time and, despite considering the structures of time of other organizations with which it has to interact, the norms and sanctions that govern the use of time in that organization in particular are applicable only to its own members. According to Blount and Janicik (2001), organizations generate norms and information that influence the way in which individuals select their temporal references.

The most impressive characteristic concerning institutional time tends to be its precedence or dominance in relation to interaction time and this, in turn, tends to have precedence over the self time of each individual. In other words, owing to the scarcity of time, the individual tends to give up self time for interaction time and this in turn for institutional time. This subordination of self times and interaction time to organizational time occurs for two reasons: first because organizational time, much 
more structured than the other two, dictates the circumstances in which interactions can take place (coffee breaks, end of the working day); secondly, because organizational time tends to determine the pace of interactions.

\section{Modern Society, Organizational Changes and Matters that Affect the Notion OF TIME}

In the understanding of Hassard (2001), excessive 'quantification' of the notion of time makes industrial society turn time and the individual into commodities of the production process, from which it attempts to continually extract additional value. Time and money are seen as interchangeable commodities: 'Time is one means by which money can be appropriated, in the same way as money can be used to buy time' (Hassard, 2001, p. 133).

Time also tends to be seen as a scarce resource or 'an object for consumption' (Hassard, 2001, p. 135) which has the potential to be consumed in a variety of activities. Thus, being treated as a scarce resource, it also becomes a boundary condition. Hassard (2001) observes that, in advanced societies, the scarcity of time makes events become more concentrated and segregated as large production systems demand segmentation, both in parts (roles and position) and activities in terms of time and space.

This instrumentalization of time in industrial society can be explained by the vision of Sorokin and Merton (1937), to whom the systems of categorization of time are the fruits of the need for social coordination. Hassard (2001) also observes that this utilization of time as an instrument of coordination and control has contributed to industrialism changing relationships at work. This has resulted in time, rather than skill or effort, becoming the main unit for measuring value and payment of individuals.

With the quickened pace of society today, Hassard (2001) comments that, in the dynamic of social life in recent decades, complexity has heightened to such an extreme level that, more than a commodity, time has come to be seen literally as having become compressed, developing the sensation that we are in an age of 'instant time' (p. 138).

Lewis and Weigert (1981) give some important considerations in terms of how, even at the level of cyclic times (cultural level), important changes have been taking place in modern society, which directly affect the lives of individuals. In the daily routine, for instance, there is a growing tendency for the time between waking up and sleeping to be filled with a variety of activities that demand a high level of synchronicity of individuals, of subordination of their self time. Most of all for those who are part of urban life in big cities, this tendency is seen not only by the numerous work-related activities, but even in activities that are supposedly linked to 'free time' such as courses, TV shows and lunch breaks. Thus, the daily routine tends to be entirely filled and synchronized, and the amount of time dedicated to each activity tends to become shorter, stealing from the social world of individuals the space for spontaneity, creativity, novelty and personal relationships. In this context, the individual who cannot manage the synchronicity of his times of his multiple activities adequately tends to be seen as incompetent.

In terms of weekly routine, Lewis e Weigert (1981) observe that today's society also tends to break from the traditional standards, as days that are supposed to be for rest or free time (weekends and public holidays) tend to become days of normal productive activity in society, as is the case of shopping centers opening on Sundays and holidays. Thus, additional difficulties for timing life are created in society.

Hassard (2001) relates some of the main characteristics that can be seen as indicators of reconfiguration and, above all, the compression of the notion of time in our society: organizational 
changes that overnight blurs the distinctions between working days and rest days, between the home and work, between leisure and work; the growing availability of products, places and images in a society that is 'ready to deliver'; fashions, ideas and images that are increasingly volatile and ephemeral; an increase in the temporary characteristic of work, careers, values and personal relationship; the proliferation of flexible forms of technology; the growth in businesses that are open 24 hours a day; the growing divorce rate and other forms of domestic break ups; a growing feeling that the pace of life has become too fast.

To Perlow (1999), given the shortness of time in modern daily life, the problems faced by individuals in the management of these different spheres of their lives in society tend to be worsened, particularly those who are at the peak of their productive age. The shortness of time and the quickened pace of life mean that these individuals tend to see time move much more quickly than a child or an older person would see it. Likewise, there are differences in the way that social status, the family situation and the type of professional activity they do interfere in the shortness and the degree of stratification of time for individuals.

Goddard (2001) highlights the fact that, also in the sphere of management in organizations, the changes that have taken place in recent decades have required a reconfiguration of the notion of time. Traditionally, work was defined in terms of hours spent within organizational space on carrying out tasks. As work has become a complex mixture of times and spaces that incorporate virtual and knowledge-intensive activities, it has become increasingly important to think of a way to combine the expectations of time dedicated to carrying out tasks and time dedicated to meeting organizational goals, which are not always compatible and may even come into conflict with one another.

In a study on the characteristics of communications in modern day organizations, Silva and Oliveira (2003) also observe that some types of change caused in organizations today end up reducing the time that individuals spend together. Since they increase pressure and the volume of work, space for personal relationships tends to be controlled by a technology that benefits the use of excessively simple and objective language.

Other authors have pointed out that the configurations of time are also associated with other dimensions that influence the way individuals attribute sense to the work of organizations and the changes they have felt in them, such as identities (Corley \& Gioia, 2000; Gádea \& Lallement, 2001; Rouleau, 1999) and gender (Benschop \& Doorewaard, 1998; Gádea \& Lallement, 2001).

Benschop and Doorewaard (1998) observe, for example, that the recent growth of women's participation in the work market has frequently been seen as involving part time work, which has helped to influence, along with other factors, the way that women feel undervalued, are underpaid and have lower career expectations when compared to their male colleagues.

In their turn, Gádea and Lallement (2001) mention studies that show that the overload of time dedicated to work by French executives (cadres) combined with the flexibilization of control over the working day of production employees, characteristics of current changes, have reduced the traditional self-perception of privilege and superiority of these executives, thereby affecting their identity. In the past, one of the aspects that sustained the identity of these executives was exactly the fact that their time was not controlled like that of the workers in the lower ranks of the hierarchy.

\section{The Methodological Characteristics of ThIS Study}

This study is the embryo of a line of cooperative research between two Brazilian management schools (here called $\mathrm{X}$ and $\mathrm{Y}$ ). This line of research is the result of the perception of similarities found in studies carried out at both institutions, which aimed to research the social dynamic, human behavior and working relations in situations of organizational change. This line of research has a data corpus 
obtained from 133 in-depth interviews with participants in changes that took place at eight organizations, resulting from two different studies that had previously been done and constituted as shown in Table 1.

Table 1: Composition of Studies that Originated the Corpora of Data for the Line of Research on Time and Space in Changing Organizations

\begin{tabular}{|c|c|c|}
\hline $\begin{array}{c}\text { General } \\
\text { Data }\end{array}$ & $\begin{array}{l}\text { Characteristics of the organizations and the situations of } \\
\text { change studied }\end{array}$ & $\begin{array}{l}\text { Main focus of the study } \\
\text { and research method }\end{array}$ \\
\hline $\begin{array}{l}\text { No. Of } \\
\text { companies } \\
\text { analyzed: } 3\end{array}$ & $\begin{array}{l}\text { A - Telecommunications service company, privatized two } \\
\text { years before the study took place; also went through a process } \\
\text { of merger with other companies; } \\
\text { B - Transport service company, privatized for years before the } \\
\text { study and acquired by a domestic group. } \\
\text { C - Electric energy distribution company, privatized four } \\
\text { years before the study and whose management was taken over } \\
\text { by foreign groups. }\end{array}$ & $\begin{array}{l}\text { Focus: the way in which the } \\
\text { organizational changes } \\
\text { affect the personal and } \\
\text { professional life of } \\
\text { individuals. } \\
\text { Method: semi-structured } \\
\text { interviews with survivors of } \\
\text { the base and middle } \\
\text { management level, with } 22 \\
\text { in organization A, } 21 \text { in B } \\
\text { and } 15 \text { in C. }\end{array}$ \\
\hline $\begin{array}{l}\text { Year: } 2001 \\
\text { No. Of } \\
\text { companies } \\
\text { analyzed: } 5\end{array}$ & $\begin{array}{l}\text { D - Private teaching and research foundation in Management } \\
\text { and Economics, whose changes were a result of a } \\
\text { reconfiguration in its structure for capturing resources. } \\
\text { E - Company from the sector of urban infrastructure services, } \\
\text { privatized four years before the study, coming under the } \\
\text { control of a foreign group. } \\
\text { F - State financial institution whose changes were the result of } \\
\text { redefined government policies for the sector and the company } \\
\text { in particular. } \\
\mathbf{G ~ - ~ I n s p e c t i o n ~ d e p a r t m e n t ~ o f ~ t h e ~ m u n i c i p a l ~ a d m i n i s t r a t i o n ~ t h a t ~} \\
\text { had been undergoing important restructuring because of a } \\
\text { modernization project for its management, in addition to being } \\
\text { submitted to successive changes of government. } \\
\text { H - Multinational in the pharmaceutical sector that had } \\
\text { undergone the third process of merger or acquisition in eleven } \\
\text { years. }\end{array}$ & $\begin{array}{l}\text { Focus: the dynamic of } \\
\text { communication and the } \\
\text { process of subjecting of } \\
\text { individuals in situations of } \\
\text { organizational change. } \\
\text { Method: semi-structured } \\
\text { interviews with survivors of } \\
\text { the base and intermediate } \\
\text { management of the } \\
\text { organizations, with } 14 \text { in } \\
\text { organization D, } 15 \text { in E, } 17 \\
\text { in F, } 14 \text { in G and } 15 \text { in H. }\end{array}$ \\
\hline
\end{tabular}

Chosen as the central goal for the inter-institutional line of research was the analysis of the dynamic that involves the configurations of space and time in situations of organizational change. For this article, we sought to restrict the focus of analysis to the temporal dimension, seeking to identify how the configurations of time affect the way individuals seek to construct meaning for changes and adjust to them. 
It is important to point out that the gathering of data from both studies in the same corpus was only possible due to the high level of similarity of the method utilized for collecting data and the content approached through interviews, in addition to the nearness in time of the two studies. We also saw that, despite the passing of four and three years, respectively, of the carrying out of the original studies, the data remained up to date and usable for the purposes of this analysis.

Once the analysis focus had been chosen, the integral content of the data from the interviews available in the corpus were reanalyzed and recategorized in order to capture the narrative of the individuals concerning their perceptions of the configurations of time in situations of the organizational change they were involved in. Given the diversity of the contexts, the analysis concentrated on the search for similarities with a higher degree of recurrence found in the narrative of the individuals who participated in the different organizations.

\section{DisCUSSION OF THE RESULTS}

Four main categories of results arose from the analysis of data: the way in which individuals characterize change around temporal events; the feeling of loss of control over time; the dominance of institutional time over interaction time and self time; the attempt of the individuals to adjust to the new configurations of time.

\section{The Characterization of Change around Temporal Events}

One of the first characteristics that naturally emerges in the discourse of the interviewees is the way in which, in the attempt to construct meaning for organizational changes, they utilize a logical structure of events to delimit comparatively the differences between the temporal 'moments' or 'phases' (expressions frequently used by interviewees) of the process. In this sense, the individuals show that they use relevant events as the main unit for marking the time of changes. It is more common to find narratives around the 'period' between two events or periods prior to and after events than the mention of precise dates or the duration of these periods, which tend to be cited only when directly asked by the interviewer. In many cases, the individuals do not even remember the year in which the events took place.

Among the eight cases studies, four concern privatization. This is a type of event which, in the view of most of the individuals of these four organizations, represents that of greatest impact, since not only the composition of the business was modified but also the dynamic of the organization and the perspective of the future of the employees. Likewise, in each of the other four cases, there is a type of event that proves to be a dominant reference point that is utilized by the individuals to characterize their perceptions on the process of changes over time.

Everything takes places as if there were a story to be told about what happened before and another about what happened after the occurrence of these central events. The stories and happenings that were told refer, for instance, to the composition of a new psychological contract, the establishment of a new form of working, greater concern with competition and customer satisfaction, the appearance of new opportunities or threats.

Nevertheless, besides these central events, the time line constructed by the individuals to characterize the evolution of the changes is marked also by events of an accessory nature, some prior to the central event and others coming afterwards, as is outlined for Organizations A to H in Figure 1. 
Figure 1: The Mode of Categorizing Change as a Temporal Structure of Events

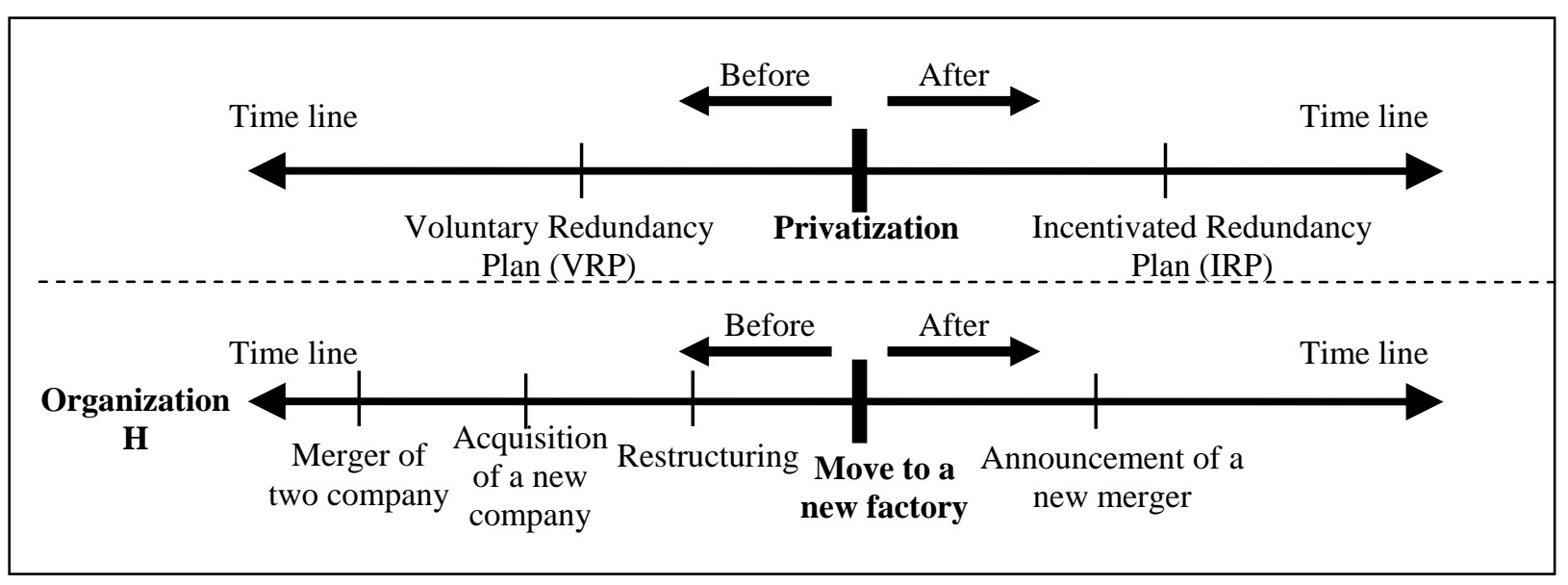

It is worth pointing out here that, in each of the organizations, although there was a high level of agreement in the different narratives, not all the individuals identified the same types of central and accessory events, nor did they always attribute the same level of importance to each event, which suggests that, despite dealing with a socially constructed process, the characterization of change takes on different meanings to each individual. However, the majority use similar structures for describing time to that shown in Figure 1, in which we see a linearity in two directions: the past (before) tends to be shown as a sequence of events (accessory events) that help us to understand the deep meaning that the central event represented to the individuals, while the present and future (after) tend to be justified as consequences of the central event and its resulting accessory events

\section{THE FEeLING OF LOSS OF CONTROL OVER TIME}

In the eight cases analyzed, despite the differences between the types of events involved in the changes, there is a coincident perception that some of the large impacts on individuals are the intensification of the work dynamic (larger volume, bigger responsibilities with smaller teams) and greater vulnerability of jobs with loss of stability and greater risks of future dismissal. In this sense, the different situations of change analyzed also have in common the fact that they provoke in individuals a feeling of weakness of their psychological contract with the organization. This feeling is common among employees from the organizations in which the changes that took place seemed to represent a lower level of breaking with the status quo, as in the cases of organizations $\mathrm{F}$ and $\mathrm{G}$.

One of the main consequences of this type of perception is that the individuals tend to identify a significant level of loss of control over their present time, which was once identified by more regular and better outlined tasks, which tend to become, nevertheless, more chaotic in the new context. The statements of the interviewees refer not only to a greater demand for time in terms of quantity but also in the pace imposed by the company. Tasks seem to be performed more quickly and there are complaints of lack of time to plan activities. The pace in which the changes take place seems to be increasingly faster, which implies changes all the time ('here things don't happen overnight, but hourly'). The acceleration of changes and the increased demand and workload tend to cause the sensation of never being up to date with their work, 'always trying to make up for lost time'.

This same feeling of loss of control over time is shown in terms of expectations for the future. In the logic prior to the changes, the individuals felt more capable of visualizing their career perspectives, even though these perspectives were not considered ideal. If beforehand the temporal background for their jobs, around which the events of their daily professional lives revolved, tended to be one of 
continuity, in the new situation, the possibility of losing their jobs suddenly became the center of attention. Their perceptions of future time were no longer characterized by a peaceful wait for retirement. Instead, they became, in some cases, worries over how long they had been at the company, how long a wait to qualify for retirement and the threat of interrupting this wait through dismissal ('time is passing and I'm getting closer to home, to reaching my goal of safety'). Even in organizations where these threats were less concrete (F and G), there was a feeling that loss of stability was 'just a matter of time'.

In the new order of facts, the future seems to be something difficult to plan, and the individual is only left with the alternative of preparing for the unexpected, seeking to construct, in the present, his chances for survival. There are also those who, believing that they have few chances of being able to make these preparations, seek to justify, in their histories about the organization and their previous lack of opportunities, their feeling of impotence when faced with these facts.

The notion of time also seems to bring new types of measurement that qualify, or at least discriminate, individuals in the organization: if 'time served' and 'seniority' were once deserving attributes, in the new order, the value of time is evaluated exclusively by productivity, the notion of usefulness of each moment, without a chance of referring to the past. Only potential is believed to be valuable, the capacity to provide immediate results in detriment of experience. Time served and chronological age therefore become distinctive marks of older employees, those who are more apt to be dismissed. Different types of organizational actions, letters calling for voluntary redundancy, talks from managers about people's ages, valuing of young trainees, are all signs that chronological age and time served at the company are factors that weigh considerably on the perspective of a future at the company.

\section{The Dominance of InStitutional Time on INTERACtion Time AND Self Time}

With the feeling of weakening of psychological contracts, the new context, therefore, leaves individuals with the feeling of greater removal, for the organization, from the power of control over the time of each individual.

Thus, institutional time comes to have increasing priority over interaction time and self time. Even the quality of certain dynamics seems to have been altered because of a new temporality imposed by the company and by the competitive environment. Decision-making processes, once carried out more hierarchical or political logic, come to require more speed ('today these decisions are quick, rapid'); exchanges of information, which used to be hierarchical, become more dynamic and faster; customer service follows competitive logic, for which speed ('the client wants this by tomorrow') is a competitive advantage.

Company demand is felt on interaction time, that time for a chat over a cup of coffee, in the corridor or even at lunch time and after working hours. There is less time and energy for getting together, for exchanging a friendly word, meaning that people 'forget about' or have no time to 'look at' a neighboring work mate, and still less one who is far away. Even for interaction outside the workplace, work seems to be taking up more and more attention and energy on the part of employees: 'you work, work, work, and even when you go out for a beer, you talk about work'.

On the other hand, there is a distinction to be drawn between interaction time dedicated to work and the time dedicated to personal interaction with colleagues. If, on the one hand, individuals perceive the latter as being strongly affected by changes, there are, on the other hand, opinions that reveal a feeling that new opportunities have been created for greater interaction at work because of less hierarchical structures, incentives for communication and even greater company informality. Some declarations show that managers have become more communicative with their subordinates, leaning towards more open communication dynamics. Others see the availability of better technological resources, such as e- 
mail as a way of breaking down traditional barriers of access to peers, superiors, subordinates and clients, keeping them connected all the time. However, there are some paradoxes in relation to these possible improvements in the use of interaction time concerning work: the biggest opening and importance attributed to communication is attenuated by the shortness of time which makes it increasingly difficult to schedule meetings or gather a team together to discuss ideas or even 'to make a phone call to solve a couple of problems', since the rush always seems to be like 'putting out a fire'; the quickened routine and the excess of information received throughout the day means that many individuals have little time to access the messages they have received, or it may be that the information they have received is so scanty that longer personal contact is required through traditional means. Or it may be that the time dedicated to interaction at work often results in a feeling of lost autonomy on the part of individuals since everything begins to follow a logic of taking care of the priorities that are seen as more of an emergency.

The sphere that has most been affected by changes seems to be the personal one: it can be said that family time or even their own time is what has suffered most. Many employees felt obliged, in the new situation, to give up part of their family duties, leaving them to the spouse and, in some cases, to grandparents and other relatives, leading to a reorganization of family time ('my family became more involved than they had been up to then: my parents, my children's godparents'). Many statements show that their attempts to adapt to the situations of organizational change did not take place without complaints from spouses and children. Likewise, the reports indicate that many personal activities, such as exercise, classes, visits to the doctor and dentist, have been constantly put off or even cancelled.

Nevertheless, despite this feeling of great predominance of institutional time over interaction and self time, many individuals revealed that the feeling that this is a face of change which is not actually determined by the organization. The changes are often seen as inevitable, the result of market pressures and decisions from higher up that are not within the control of the organization, resulting from the characteristics of 'today's' society.

\section{The CONFIGURATIONS OF TIME AND THE ATTEMPT bY INDIVIDUALS to ADAPT}

One aspect that was common to the discourse of several of the interviewees is the fact that, in a context of change that greatly transforms their personal or professional lives, they attempt to make sense of the continuity of their history, seeking new readings on their past and reconstructing their present and future expectations, assuming as a temporal framework the events that they consider to be central.

Some discourses reveal, for instance, that their feelings of friendship towards old comrades must be reviewed because turnover has increased and new people appear and therefore new relationships must be consolidated. However, these new relationships must be constructed on new bases, since the opportunities to do it are fragmented amidst a routine of work that tends to be increasingly faster. They therefore admit to a certain conformity when it comes to recognizing that the former level of relationship is no longer possible. Some notice at this point that they need to seek new types of relationships with their colleagues, who are generally younger and are not part of their story in the organization. There are those who, therefore, seek to assimilate the characteristics of this new group, attempting to become younger (some have confessed that they even change their style of dress), changing their discourse to include the terms coined by the organization and by their new colleagues, or seeking recycling, back to school. Others take a less optimist view of their chances for selftransformation, trying to construct a type of protected action, plunging into their work as a way of protecting themselves from the prejudiced looks that may classify them as outdated and threaten their survival in the organization. 
As for plans for the future, some see in the situation of change at work an opportunity to review the projects of their career, considering the possibility of moving to another organization or even profession. There are also those who, not seeing the opportunities to reverse the course of their professional history, come to view their future at the organization as a race against the clock, surviving until they reach retirement. There are also those who see changes in course as a chance for growth that had not been offered to them by the organization before.

However that may be, the individuals predominantly reveal a feeling that the direction of the future is increasingly under their responsibility and less determined by the organization, which, confronted by a feeling of loss of control over their own time, generates a paradox that is difficult to resolve. How individuals articulate this paradox is not clear in their discourses. However, the anxiety revealed through the need to adjust to new times, shows that they see changes as a proposal for a reality with schizophrenic characteristics since if the future is more in 'their own' hands, time and its use seems to be increasingly under the control of others, of organizations and society. This type of paradox, which is frequent nowadays, tends to make people feel, as Sennett (1999) observes, 'feel led astray'.

\section{CONCLUSIONS}

Organizations undergo changes during their existence and the emphasis of employees on these changes seems to be linked to the impact these changes have on their professional and personal lives. Among the most important aspects that influence the perceptions and feelings of individuals, according to what has been suggested by the authors mentioned in the theoretical reference framework and confirmed by the results of this study, is the way in which it is understood that changes affect the notion of time.

Lewis and Weigert (1981) propose a conceptual structure that has proved to be interesting for the aims of this article: to analyze how configurations of time influence the way in which individuals construct the meaning of changes and seek to adjust themselves to these new contexts. The main characteristic of such a structure which, in the view of these authors, is a reference framework for understanding the construction of meaning on social time, is the fact that there appears to be a precedence or dominance of the perceptions relating to the macro level of reality (socio-cultural time and institutional time) on the micro level (interaction time and social time). The results show that, in situations of changes promoted in current organizations, this relationship of precedence tends to be largely responsible for the anguish and concerns of individuals, who perceive the need to reorganize the way in which they configure time and deal with it in order to adapt to the new reality.

These results also allow us to complement the analysis structure originally proposed by Lewis and Weiger (1981) in that it is observed that, when attempting to construct meaning for the different levels of social reality in situations of change, individuals do it comparatively, through confronting previous and later contextual characteristics of temporal events which they consider to be central. Thus, each level of reality tends to be evaluated by individuals in terms of how the relevant events that characterize the course of changes influence their capacity to deal with the demands of time. This is a structure of thought that seems to divide reality according to a logic of 'before' and 'after' central events, sometimes aided by the identification of other accessory events that help to explain the past and better identify the characteristics of the present and expectations for the future.

The results of this analysis therefore allow for the proposition of a reference framework for the attempt to understand how individuals construct their configurations of time in situations of organizational change, as shown in Figure 2. 


\section{Figure 2: Reference Framework for the Analysis of the Configuration of Time in Situations of Organizational Change}

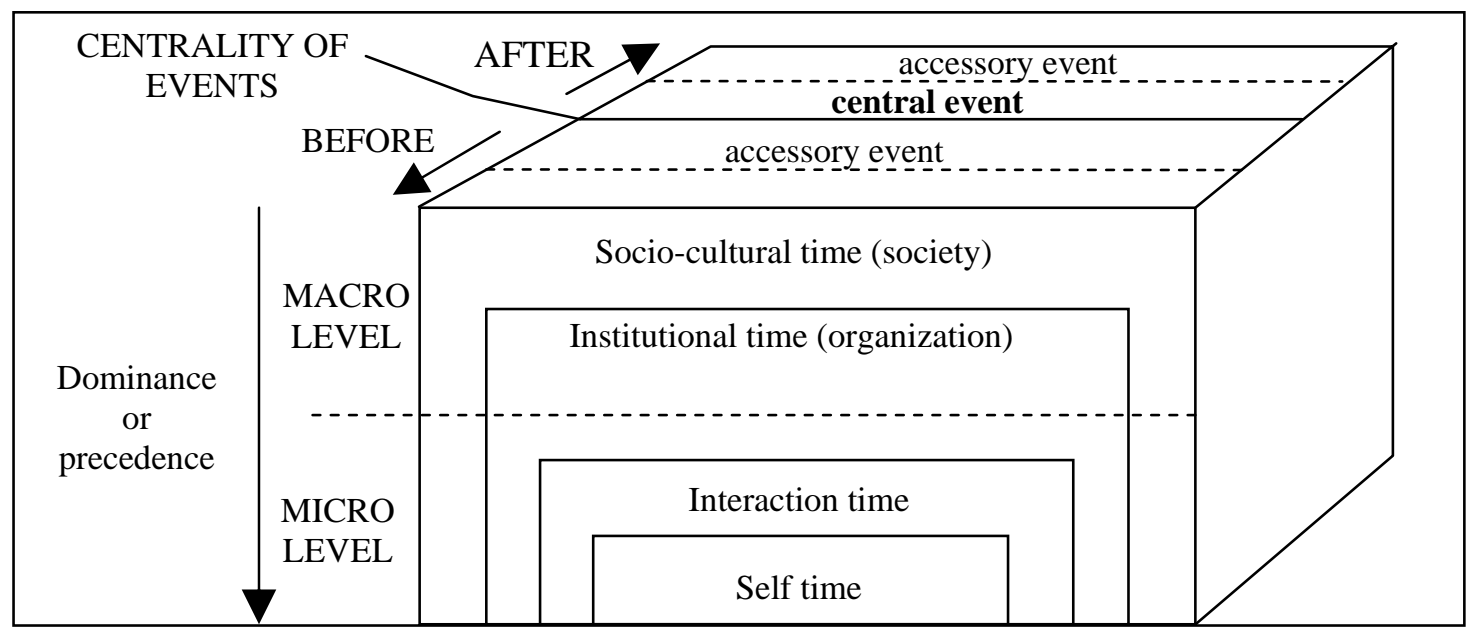

The results also show that these configurations are greatly influenced by the discourse and actions of organizations in their attempt to manage changes, and compose an important basis for individuals to construct their positioning and actions.

It is hoped that this reference framework can serve as a basis for other studies that seek to understand the process of construction of meaning of changes and how this process can be linked to space-time considerations by individuals.

\section{NOTE}

\footnotetext{
${ }^{1}$ This study was made possible by the financial aid of the National Council for Scientific and Technological Development (CNPq), through their research project in the fields of Human, Social and Applied Social Sciences (Process No. 401416/2004-6).
}

\section{REFERENCES}

Allaire, Y., \& Firsirotu, M. (1989). How to implement radical change in large organizations. In M. L. Tushman, C. O’Reilly, \& D. A. Nadler (Orgs.). The management of organizations. New York: Haper Collins.

Armenakis, A. A., \& Bedeian, A. G. (1999). Organizational change: a review of theory and research in the 1990’s. Journal of Management, 25(3), 293-315.

Bareil, C., \& Savoie, A. (1999). Comprendre et mieux gerer les individus en situation de changement organisationnel. Gestion - revue internationale de gestion, 24(3), 86-95.

Benschop, Y., \& Doorewaard, H. (1998). Covered by equality: the gender subtext of organizations. Organization Studies, 19(5), 787-805. 
Block, R. A., Buggie, S. E., \& Matsui, F. (1996). Beliefs about time: cross-cultural comparisons. Journal of Psychology, 130(1), 5-22.

Blount, S., \& Janicik, G. A. (2001). When plans change: examining how people evaluate timing changes in work organizations. The Academy of Management Review, 26(4), 566-585.

Corley, K. G. \& Gioia, D. A. (2000). Organizational identity in transition over time. In C. L. Cooper \& D. M. Rousseau (Eds.). Trends in organizational behavior: Vol. 7. Time in organizational behavior. Chichester, England : Wiley.

Demers, C. (1993). Communication et changement dans les organisations. Communication et Organisation, (3), 94-127.

Ford, J. D., \& Ford, L. W. (1995). The role of conversations in producing change in organizations. Academy of Management Review, 20(3), 541-570.

Gadéa, C., \& Lallement, M. (2001). French sociology and time: origin, development, and current research. KronoScope, 1(1-2), 101-128.

Giddens, A. (1984). The constitution of society. Berkeley: University of California Press.

Giordano, Y. (1998). Communication et organisations: une réconsidération par la théorie de la structuration. Revue de Gestion de Ressources Humaines, (26-27), 20-35.

Glucksmann, M. A. (1998). What a difference a day makes: a theoretical and historical exploration of temporality and gender. Sociology, 32(2), 239-258.

Goddard, R. (2001). Time in organizations. The Journal of Management Development, 20(1), 19-27.

Hassard, J. (2001). Commodification, construction and compression: a review of time metaphors in organizational analysis. International Journal of Management Reviews, 3(2), 131-140.

Isabella, L. A. (1990). Evolving interpretations as a change unfolds: how managers construe key organizational events. Academy of Management Journal, 33(1), 7-41.

Ketz de Vries, M. F. R., \& Balazs, K. (1999). Transforming the mind-set of organization. Administration and Society, 30(6), 640-675.

Kotter, J. P. (1995). Leading change: why transformation efforts fail. Harvard Business Review, 73(2), 59-68.

Lee, H., \& Liebenau, J. (1999). Time in organizational studies: towards a new research direction. Organization Studies, 20(6), 1035-1058.

Lewis, J. D., \& Weigert, A. J. (1981). The structures and meanings of social time. Social Forces, $60(2), 432-462$.

Newton, T. (2003). Crossing the great divide: time, nature and the social. Sociology, 37(3), 433-457.

Perlow, L. A. (1999). The time famine: toward a sociology of work time. Administrative Science Quarterly, 44(1), 57-83.

Rouleau, L. (1999). Le <<Malaise $>>$ du changement intermediaire en contexte de reorganisation: éclatement et renouvellement identitaires. Gestion - revue internationale de gestion, 24(3), 96101.

Sennett, R. (1999). A corrosão do caráter. Rio de Janeiro: Record.

Silva, J. R. G., \& Oliveira, M. C. L. (2003). A composição de um quadro de referência para a gestão 
da comunicação organizacional. Anais do Encontro Nacional dos Programas de PósGraduação em Administração, Atibaia, SP, Brasil, 27.

Silva, J. R. G., \& Vergara, S. C. (2003); Sentimentos, subjetividade e supostas resistências à mudança organizacional. Revista de Administração de Empresas, 43(3), 10-21.

Sorokin, P. A., \& Merton, R. K. (1937). Social time: a methodological and functional analysis. The American Journal of Sociology, 42(5), 615-629.

Vince, R., \& Broussine, M. (1996). Paradox, defense and attachment: accessing and working with emotions and relations underlying organizational change. Organization Studies, 17(1), 1-21.

Weick, K. E. (1995). Sensemaking in organizations. London: Sage.

Weick, K. E., \& Quinn, R. E. (1999). Organizational change and development. Annual Review of Psychology, 50(1), 361-386. 